\title{
Comparison of two-dimensional echocardiographic wall motion and wall thickening abnormalities in relation to the myocardium at risk
}

\author{
Andrew J. Buda, M.D., Rainer J. Zotz, M.D., Diane P. Pace, B.S., and \\ Lisa C. Krause, M.A. Ann Arbor, Mich.
}

Following acute coronary occlusion, a left ventricular functional abnormality is visualized by twodimensional echocardiography (2D E) within seconds. ${ }^{1-5}$ Numerous investigators have attempted to measure this functional abnormality and correlate it to risk area ${ }^{5}$ or infarct size..$^{1-4}$ However, there continues to be no consensus on the use of endocardial wall motion or wall thickening as the most appropriate index of ischemic dysfunction. Although, theoretically, the extent and degree of wall motion and wall thickening abnormalities should correspond during acute myocardial ischemia, the complex threedimensional motion of the heart during systolic contraction and the particular coordinate system used for quantitative analysis may alter this relationship. To evaluate potential differences between regional wall motion and wall thickening measures of functional abnormality, we examined 27 dogs during acute coronary occlusion and compared the extent of the functional abnormality to the size of the myocardium rendered ischemic.

\section{METHODOLOGY}

Animal model. A total of 27 anesthetized, openchest dogs, weighing between 18 and $23 \mathrm{~kg}$, were studied. Each animal was anesthetized with sodium pentobarbital and underwent a left thoracotomy through the fifth intercostal space. Polyvinyl cathe-

From the Cardiology Division, Department of Internal Medicine, University of Michigan Medical School.

Supported in part by a grant-in-aid from the American Heart Association of Michigan and grant HL 29716 from the Natiunal Heart, Lung, and Blood Institute, National Institutes of Health, Bethesda, Md.

Received for publication July 22, 1985; accepted Aug. 20, 1985.

Reprint requests: Andrew J. Buda, M.D., Cardiology Division, 3910G, University of Michigan Medical Center, 1500 E. Medical Center Dr., Ann Arbor, MI 48109-0366. ters were inserted into the left internal jugular vein for fluid and drug administration, into the ascending aorta for measurement of mean aortic pressure, and into the left atrium for subsequent injection of radioactive microspheres. The animal then underwent a limited right thoracotomy to allow placement of the 2D E transducer directly on the heart using the right ventricle as a standoff. A $2 \mathrm{~cm}$ section of the left circumflex coronary artery was freed by dissection and a snare occluder was placed around it.

Experimental protocol. 2DE was performed by means of a Diasonic $3400 \mathrm{R}$ scanner and a $2.25 \mathrm{MHz}$ transducer. Images were recorded on a videocassette using a Panasonic recorder for later analysis. The 2DE transducer was placed through the limited right thoracotomy directly on the right ventricle which served as a baffle to allow full visualization of the circumferential extent of the left ventricle in the short-axis projection. The left ventricle was scanned from aortic valve to the apex in the short-axis projection, and the midposterior papillary muscle position was identified. Once identified, baseline hemodynamic and 2DE data were acquired.

The left circumflex coronary artery was then abruptly occluded and, at approximately 30 minutes following occlusion, a repeat $2 \mathrm{DE}$ study was performed in the same short-axis projection using the posterior papillary muscle as an internal landmark. Immediately thereafter, 600,000 technetium -99 radioactive microspheres $(20 \mu$ diameter $)$ were injected into into the left atrium for subsequent autoradiographic analysis of the at-risk, jeopardized myocardium.

Autoradiographic analysis. The animals were killed with potassium chloride injection and the hearts excised. The left ventricle was dissected free of the surrounding tissue, cooled in a freezer for 15 


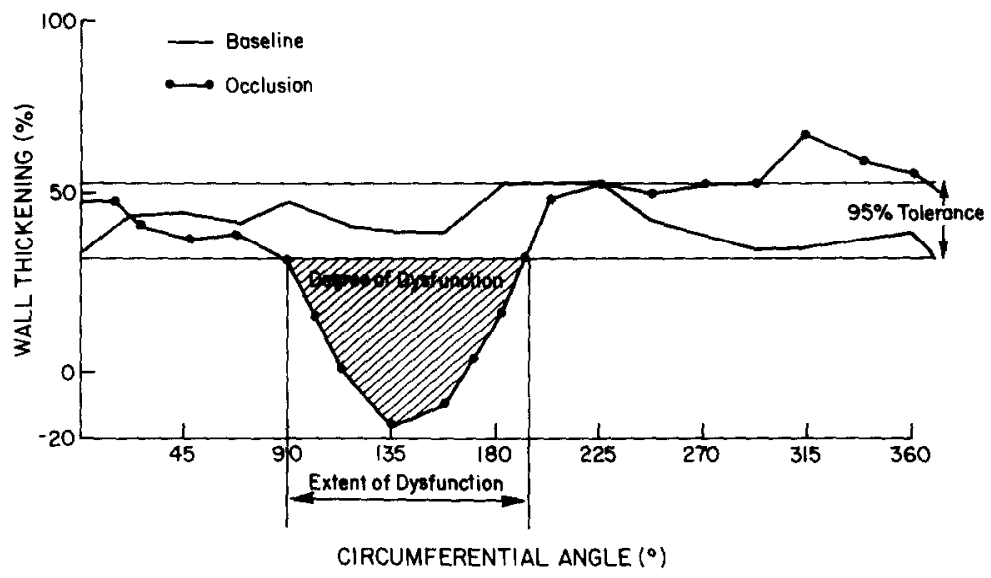

Fig. 1. Method of measuring circumferential extent and degree of left ventricular dysfunction from the left ventricular regional wall thickening map. See text for details. In this animal study, the extent of wall thickening abnormality is 153 degrees and the degree of dysfunction (hatched area) measures $21 \mathrm{~cm}^{2}$.

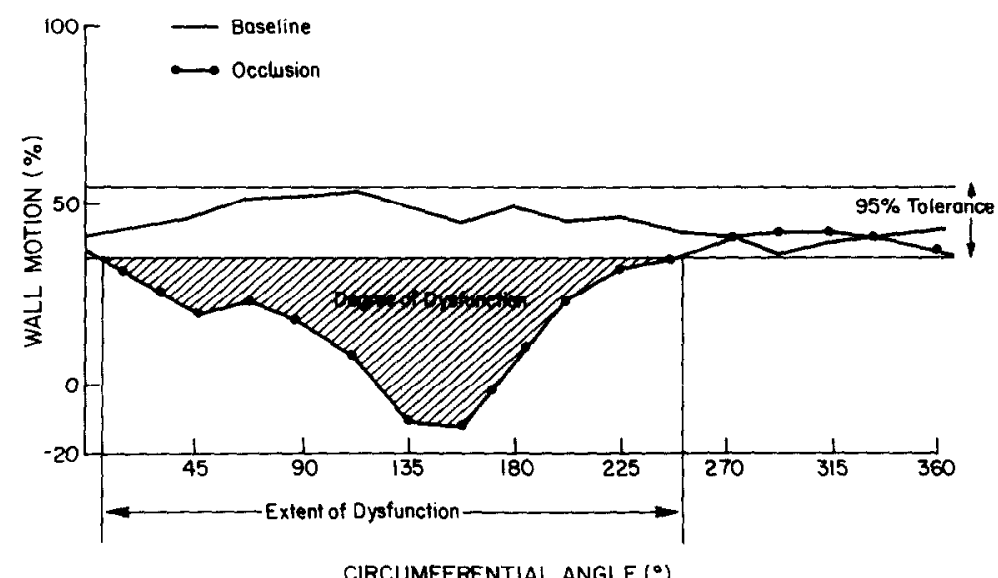

Fig. 2. Method of measuring circumferential extent and degree of left ventricular dysfunction from the left ventricular endocardial wall motion map. See text for details. In the same animal study as in Fig. 1, the extent of wall motion abnormality is 245 degrees and the degree of dysfunction is $33 \mathrm{~cm}^{2}$. Both values are greater than those derived by wall thickening measurements.

minutes, and sliced into $5 \mathrm{~mm}$ transverse sections. For in vivo area at-risk determination, the $5 \mathrm{~mm}$ slices of the left ventricle were exposed for 18 hours on an $8 \times 10$ inch sheet of high-speed $x$-ray film and developed in an X-Omat automatic processor. Normally perfused tissue appeared as an area of high radiographic density on the final autoradiogram. whereas hypoperfused tissue appeared as an area of lower or absent radioactivity. ${ }^{6}$ All slices were traced and the endocardial and epicardial margins were traced on a clear acetate overlay. By superimposing the tracing over the autoradiogram, the boundary of the hypoperfused area was drawn at the end of the zone of decreased radiographic density by eye. The midpapillary muscle slice corresponding to the $2 \mathrm{DE}$ was identified and the endocardial circumferential extent of hypoperfused myocardium was measured in degrees with a protractor.

2DE analysis. With the use of a Diasonics CRC minicomputer-based video digitizing system, enddiastolic and end-systolic frames were selected for analysis by means of the onset of the $Q$ wave in lead II to define end diastole and the smallest ventricular cavity to define end systole. An observer carefully traced endocardial and epicardial borders directly from the video display using a digitizing tablet for three consecutive beats. We have previously validated our 2DE measurements by means of a specially constructed phantom ${ }^{7}$ and in vivo. ${ }^{8,9}$ Quantitative analysis was performed with the use of a radial contraction model and a fixed diastolic center of mass at 22.5-degree intervals over the full 360- 
Table I. Hemodynamic and global left ventricular parameters

\begin{tabular}{lrl}
\multicolumn{1}{c}{ Parameters } & Control & Occlusion \\
\hline Heart rate (bpm) & $124 \pm 5$ & $134 \pm 5$ \\
Mean arterial pressure & $102 \pm 4$ & $109 \pm 4^{*}$ \\
$\quad(\mathrm{~mm} \mathrm{Hg})$ & & \\
LV end-diastolic area $\left(\mathrm{cm}^{2}\right)$ & $11.6 \pm 0.6$ & $15.0 \pm 0.7 \dagger$ \\
LV end-systolic area $\left(\mathrm{cm}^{2}\right)$ & $5.9 \pm 0.4$ & $10.6 \pm 0.6 \dagger$ \\
LV area ejection fraction & $50.0 \pm 1.7$ & $30.3 \pm 1.6 \dagger$ \\
$\left(\begin{array}{l}(1) \\
\hline\end{array}\right.$ & & \\
\hline
\end{tabular}

$\mathrm{LV}=$ left ventricular.

${ }^{*} p<0.05$.

$\dagger p<0.0005$.

degree circumference. For correction of rotation, the midpoint of the posterior papillary muscle was fixed at 135-degrees. Endocardial motion was measured as: regional ejection fraction $=$ end-diastolic area - end-systolic area/end-diastolic area $\times 100 \%$. Wall thickening was calculated as: end-systolic wall thickness - end-diastolic wall thickness/end-diastolic wall thickness $\times 100 \%$.

For each measured parameter, the mean \pm standard deviation was calculated for three normal beats and $95 \%$ tolerance limits for normal were established in each individual animal. A functional map of the normal range of endocardial motion or wall thickening for each individual animal was used for comparison with occlusion values. Abnormally reduced functional parameters were expressed as the circumferential extent (degrees) and degree of dysfunction $\left(\mathrm{cm}^{2}\right)$, measured directly from each individual animal occlusion function map. The extent of this dysfunction was measured at the curve intercepts between the occlusion and normal maps. The degree of this dysfunction was measured as the planimetered area of the map that was abnormal (Figs. 1 and 2).

Statistical analysis. All data are expressed as mean \pm standard error of the mean. Statistical comparison of values was made by means of two-way analysis of variance and paired $t$ tests, as appropriate. The probability $(p)$ was considered to be statistically significant when $<0.05$.

\section{OBSERVATIONS}

Hemodynamic and global left ventricular parameters are summarized in Table I. Following coronary artery occlusion, there was no change in heart rate but a small increase in mean arterial pressure. Each animal developed, within seconds of occlusion, an obvious wall motion abnormality visible on $2 \mathrm{DE}$ in the region of the posterior papillary muscle corresponding to the perfusion bed of the left circumflex

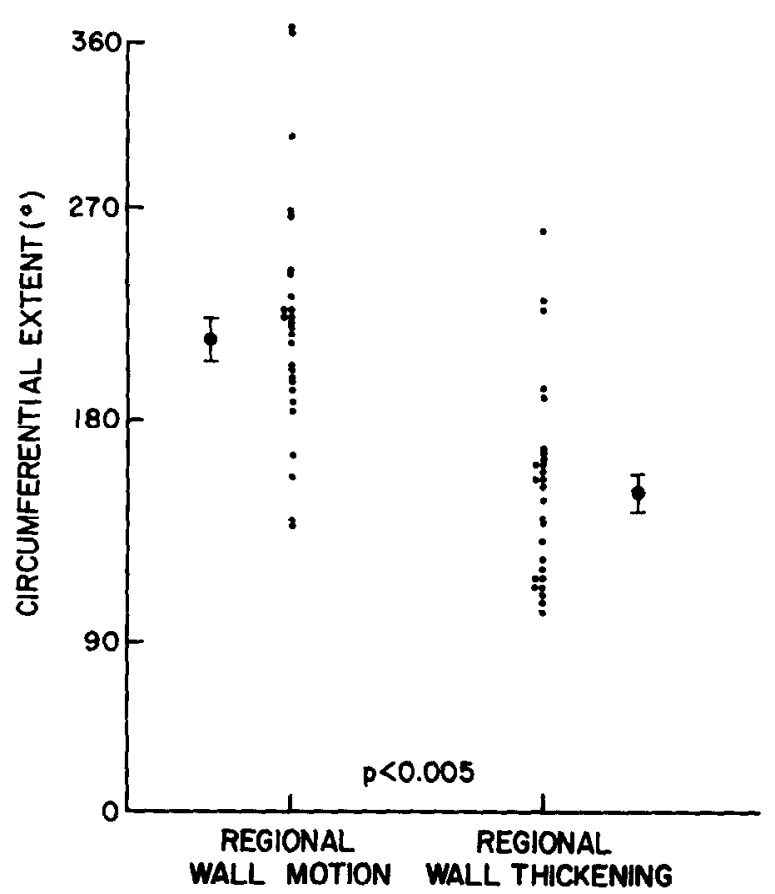

Fig. 3. Individual data points for circumferential extent of wall motion and wall thickening abnormalities following coronary occlusion. The circumferential extent of wall motion abnormality significantly overestimates the circumferential extent of wall thickening abnormality.

coronary artery. Both left ventricular end-diastolic area and left ventricular end-systolic area increased $(p<0.0005)$ producing a significant decrease in left ventricular area ejection fraction from $50 \%$ to $30 \%$ $(p<0.0005)$.

The circumferential extent of regional wall motion abnormality measured $266 \pm 11$ degrees and significantly overestimated the circumferential extent of regional wall thickening abnormality by $54 \%$ (Fig. 3). In addition, the degree of dysfunction by regional wall motion was $59 \%$ greater than that by regional wall thickening $(p<0.0005)$ (Fig. 4$)$. The hypoperfused risk area measured $128 \pm 7$ degrees or $36 \%$ of the left ventricular circumference for the midpapillary muscle slice. When the regional parameters were further compared to the hypoperfused risk area, the circumferential extent of regional wall motion abnormality overestimated the area at risk by $77 \%(p<0.0005)$, whereas the circumferential extent of regional wall thickening abnormality corresponded better to the area at risk and overestimated it by only $15 \%(p=$ NS) (Fig. 5$)$.

\section{COMMENTS}

Our data indicate that 2DE left ventricular regional wall motion abnormality, by means of our specific radial contraction coordinate system, signif- 


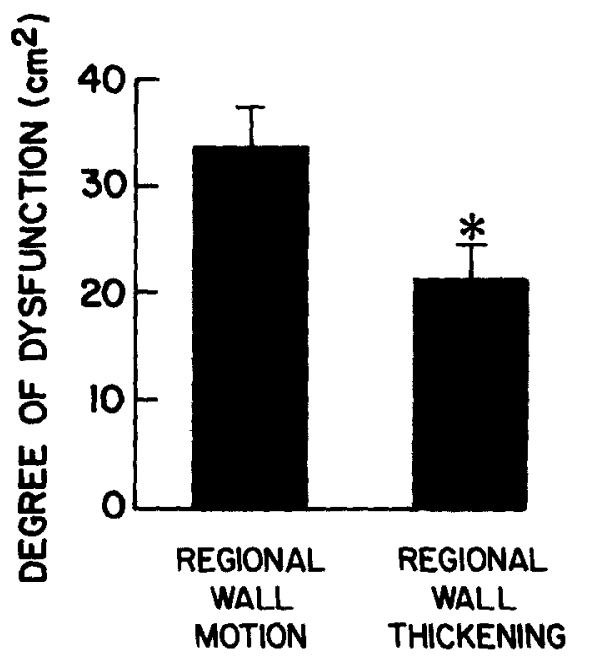

$* p<0.0005$

Fig. 4. The degree of dysfunction measured directly from the regional function maps. The degree of dysfunction by wall motion significantly overestimates the degree of dysfunction by wall thickening.

icantly overestimates both 2DE regional wall thickening abnormality and the myocardial area as risk following an abrupt coronary occlusion. The $2 \mathrm{DE}$ regional wall thickening abnormality, determined by precisely the same coordinate system, however, corresponds better to the actual ischemic myocardium. Our results generally agree with previous reports by Lieberman et $\mathrm{al}^{3}$ and $\mathrm{O}^{\prime}$ Boyle et $\mathrm{al} .{ }^{10}$ Lieberman et al. ${ }^{3}$ studied dogs 48 hours after coronary occlusion and found that both regional abnormalities of endocardial motion and wall thickening abnormalities distinguished infarcted from noninfarcted myocardium. However, they found that wall thickening was a more precise discriminator, although no data comparing circumferential extent of dysfunction were presented. O'Boyle et al. ${ }^{10}$ studied closed-chest dogs at 48 hours and later following acute coronary occlusion. They found that both endocardial motion and wall thickening were equally sensitive in detecting infarction. Although abnormalities of endocardial motion and wall thickening both correlated with infarct size, endocardial motion abnormality overestimated infarct size to a greater extent than did wall thickening abnormality. Thus these reports indicate that wall thickening abnormality by 2DE may be a more precise indicator of risk region and subsequent infarct size than endocardial motion.

In contrast to these reports, Pandian et al., in a study examining different infarct sizes, found little difference between the detection of infarction by

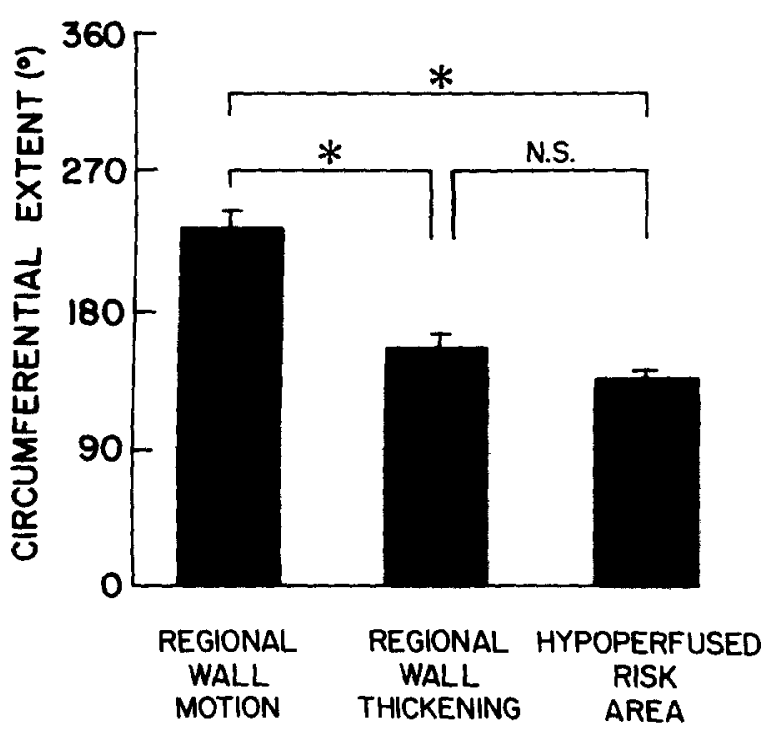

$* p<0.0005$

Fig. 5. The circumferential extent of wall motion and wall thickening abnormalities compared to actual myocardial area at risk. Note that the circumferential extent of wall motion abnormality significantly overestimates the area at risk, whereas the extent of wall thickening abnormality is no different than the area at risk.

means of endocardial motion versus wall thickening. However, they did not specifically address in their study whether the circumferential extent of wall motion and wall thickening abnormalities differed. It is possible that these two parameters, although equally sensitive, produce variable information in terms of circumferential or sizing information of ischemic and/or infarcted myocardium.

A number of quantitative schemes for measuring regional left ventricular abnormality by $2 \mathrm{DE}$ have been proposed. ${ }^{11-16}$ There has been no consensus as to the most appropriate method. Schnittger et al. ${ }^{15}$ recently compared 44 different reference methods in each of three echo views and found that a fixed external reference system was optimal for the shortaxis view at the papillary muscle level. For this reason, we employed a fixed external coordinate system for both endocardial wall motion and wall thickening measurements. Although there are inherent problems with all coordinate systems that use a centroid approach, ${ }^{17,18}$ this is still the most common analytic approach to $2 \mathrm{DE}$ data. There are clear advantages to using a noncoordinate approach to left ventricular functional analysis which may be possible through global or regional shape parameters. ${ }^{18}$ However, these approaches remain in a developmental stage and require further validation. Sim- 
ilarly, there are advantages to analyzing regional information throughout the entire cardiac cycle rather than only in end-diastolic and end-systolic frames, ${ }^{16}$ but this approach is extremely time consuming and would require automatic edge detection before proving to be of practical advantage. ${ }^{14}$

Previous investigators have used wall thickening by ultrasonic crystals as an indicator of regional contractile performance and as a measure of integrated function across all layers of the myocardium. ${ }^{19,20}$ Wall thickening has been demonstrated to have a close coupling to decreases in subendocardial blood flow and thus serves as a sensitive indicator of myocardial ischemia. ${ }^{20} \mathrm{~A}$ potential criticism of the use of wall thickening measurements as an index of left ventricular regional function is that this method does not differentiate between true systolic wall thickening and spurious increases in this variable caused by translational or rotational "shear" movements of the left ventricular wall. However, by means of a triangulation technique for studying segmental wall thickness, Osakada et al. ${ }^{21}$ have shown that the contribution of these factors to segmental wall thickness measurements is trivial.

Previous experimental studies have found regional nonuniformity of contraction and marked animal to animal variability, which in combination produce extremely large confidence limits of normal regional left ventricular function. ${ }^{22,23}$ This is further complicated by individual animal variability in the perfusion bed of the occluded coronary artery. As a result, several investigators ${ }^{5,23}$ have suggested using strict criteria, such as thinning or dyskinesis, as indicators of ischemic abnormality. However, we have observed major regional abnormalities with coronary occlusion in some dogs without actual thinning or dyskinesis. Thus, to avoid these potential false negatives, we have used tolerance limits for normality in each individual animal. This approach avoids problems related to large interanimal variability and subsequent definition of abnormality.

Our observations have important clinical implications concerning the sizing of ischemic abnormality with the use of ventricular functional data by $2 \mathrm{DE}$ and other cardiac imaging modalities. Wall thickening, by virtue of the fact that it is calculated as a relative index and is less coordinate dependent, should be used as the standard for measurement of the size of the ischemic abnormality. Endocardial wall motion, on the other hand, is significantly more coordinate dependent and may tend to overestimate the actual functional abnormality. Therefore, although both parameters are sensitive indicators of ischemic dysfunction, possible differences between endocardial wall motion and wall thickening abnormalities should be considered when evaluating the circumferential extent of ischemic myocardium.

\section{SUMMARY}

Previous 2DE studies have suggested that left ventricular wall thickening determinants of regional left ventricular function may be more precise than left ventricular wall motion parameters in the assessment of myocardial ischemia and infarction. To study the relationship between regional wall motion and regional wall thickening abnormalities relative to myocardial ischemia, we performed $2 \mathrm{DE}$ in 27 dogs at baseline and following 1 hour of circumflex coronary occlusion. A 2DE circumferential map of regional wall motion and regional wall thickening was generated at 22.5-degree intervals over 360 degrees using a fixed centroid. With the use of three consecutive beats, $95 \%$ normal tolerance levels were derived for each individual left ventricular function map. The circumferential extent of left ventricular dysfunction was measured at the curve intercepts of the occluded and normal maps. The left ventricular ischemic area at risk for the corresponding $2 \mathrm{DE}$ slice was determined by technetium99 autoradiography. Following coronary occlusion, left ventricular end-diastolic area increased $(p<0.0005)$, left ventricular end-systolic area increased $(p<0.0005)$, and left ventricular area ejection fraction decreased $(50 \pm 2 \%$ to $30 \pm 2 \%$, $p<0.0005$ ). The circumferential extent of regional wall motion overestimated the area at risk by $77 \%$ (226 \pm 11 degrees vs $128 \pm 7$ degrees, $p<0.0005$ ), whereas the circumferential extent of regional wall thickening corresponded to the area at risk (147 \pm 9 degrees vs $128 \pm 7$ degrees, $p=N S$ ). In addition, the circumferential extent of regional wall motion overestimated regional wall thickening by $54 \%$ $(p<0.0005)$. We conclude that regional wall thickening abnormality corresponds better to actual area at risk and that regional wall motion overestimates the extent of regional dysfunction. This overestimation most likely relates to the use of the centroid method of analysis which influences regional wall motion more than regional wall thickening.

\section{REFERENCES}

1. Meltzer RS, Woythaler JN, Buda AJ, Griffith JC, Harrison WD, Martin RP, Harrison DC, Popp RL: Two-dimensional echocardiographic quantification of infarct size alteration by pharmacologic agents. Am J Cardiol 44:257, 1979.

2. Wyatt HL, Meerbaum S, Heng MK, Rit J, Gueret P, Corday $\mathrm{E}$ : Experimental evaluation of the extent of myocardial 
dyssynergy and infaret size by two-dimensional echocardiography. Circulation 63:607, 1981 .

3. Lieberman AN, Weiss JL, Jugdutt BI, Becker LC, Bulkley BH, Garrison JC, Hutchins GM, Kallman CA, Weisfeldt ML: Two-dimensional echocardiography and infarct size: relationship of regional wall motion and thickening to the extent of myocardial infarction in the dog. Circulation 63:739, 1981.

4. Nieminen M, Parisi A, O'Boyle JE, Folland ED, Khuri S, Kloner RA: Serial evaluation of myocardial thickening and thinning in acute experimental infarction: Identification and quantification using two-dimensional echocardiography. Circulation 66:174, 1981.

5. Pandian N, Koyanagi S, Skorton D, Collins C, Marcus M, Kerber R: Relations between two-dimensional echocardiographic wall thickening abnormalities, myocardial infarct size and coronary risk area in normal and hypertrophied myocardium in dogs. Am J Cardiol 52:1318, 1983.

6. DeBoer LWV, Strauss HW, Kloner RA, Rude RE, Davis RF, Maroko PR, Braunwald E: Autoradiographic method for measuring the ischemic myocardium at risk: Effects of verapamil on infarct size following experimental coronary artery occlusion. Proc Natl Acad Sci 77:6119, 1980.

7. Zotz R, Meyer CR, Delp EJ, Bookstein FL, Buda AJ: Reliability of measurements from two-dimensional echocardiographic images using a cardiac phantom. Clin Res 33:240A, 1985.

8. Weiss RJ, Buda AJ, Pasyk S, O'Neill WW, Keyes JW Jr, Pitt B: Non-invasive quantification of jeopardized myocardial mass using two-dimensional echocardiography and thallium201 tomography. Am J Cardiol 52:1340, 1983.

9. Buda AJ, Pasyk S, O'Neill WW, Harkness B $\Lambda$, Pitt B, Keyes JW Jr: Relationship between myocardial perfusion and function following coronary reflow in the canine heart using single photon emission computed tomography and two-dimensional echocardiography. AM HEART J 109:1375, 1985.

10. O'Boyle JE, Parisi AF, Nieminen M, Kloner RA, Khuri S: Quantitative detection of regional left ventricular contraction abnormalities by 2 -dimensional echocardiography. Comparison of myocardial thickening and thinning and endocardial motion in a canine model. Am J Cardiol 51:1732, 1983.

11. Pandian NG, Skorton DJ, Collins SM, Koyonagi S, Kieso R, Marcus ML, Kerber RE: Myocardial infarct size threshold for two-dimensional echocardiographic detection: Sensitivity of systolic wall thickening and endocardial motion abnormalities in small versus large infarcts. Am $J$ Cardiol 55:551, 1985.

12. Moynihan P, Parisi A, Feldman C: Quantitative detection of regional left ventricular contraction abnormalities by twodimensional echocardiography. I. Analysis of methods. Circu lation 63:752, 1981.

13. Henschke CI, Risser TA, Sandor T, Hanlon WB, Neumann A, Wynne J: Quantitative computer-assisted analysis of left ventricular wall thickening and motion by 2-dimensional echocardiography in acute myocardial infarction. Am J Cardiol 52:960, 1983

14. Buda AJ, Delp EJ, Meyer CR, Jenkins JM, Smith DN, Bookstein FL, Pitt B: Automatic computer processing of digital two-dimensional echocardiograms. Am J Cardiol 52:384, 1983.

15. Schnittger I, Fitzgerald PJ, Gordon EP, Alderman EL, Popp $\mathrm{RL}$ : Computerized quantitative analysis of left ventricular wall motion by two-dimensional echocardiography. Circulation 70:242, 1984.

16. Gillam LD, Hogan RD, Foale RA, Franklin TD, Newell JB, Guyer DE, Weyman AE: A comparison of quantitative echocardiographic methods for delineating infarct-induced abnormal wall motion. Circulation 70:113, 1984.

17. Clayton PD, Jeppson GM, Klausner SC: Should a fixed external reference system be used to analyze left ventricular wall motion? Circulation 65:1518, 1982.

18. Bookstein FL, Gallagher KP, Buda AJ: Mean tensor analysis of left ventricular wall motion. IEFE Computers in Cardiology 11:513, 1984.

19. Sasayama S, Franklin D, Ross J Jr, Kemper WS, McKown D: Dynamic changes in left ventricular wall thickness and their use in analyzing cardiac function in the conscious dog. Am J Cardiol 38:870, 1976.

20. Gallagher KP, Kumada T, Kaziol J $\Lambda$, McKown MD, Kemper WS, Ross J Jr: Significance of regional wall thickening abnormalities relative to transmural myocardial perfusion in anesthetized dogs. Circulation 62:1266, 1980.

21. Osakada G, Sasyama S. Kawai C, Kirahawa A, Kemper WS, Franklin D, Ross J Jr: The analysis of left ventricular wall thickness and shear by an ultrasonic triangulation technique in the dog. Circ Res 47:173, 1980.

22. Pandian N, Skorton D, Collins S, Falsetti H, Burke E, Kerber RE: Heterogeneity of left ventricular segmental wall thickening and excursion of two-dimensional echocardiograms of normal humans. Am J Cardiol 51:1667, 1983.

23. Haendchen RV, Wyatt HL, Maurer G, Zwehl W, Bear M, Meerbaum S, Corday E: Quantitation of regional cardiac function by two-dimensional echocardiography. I. Patterns of contraction in the normal left ventricle. Circulation 67:1234, 1983. 